\title{
Estimation of rutting characteristics of waste tire rubber-modified asphalt binder using GPC
}

\author{
K. W. Kim ${ }^{1}$, S. Lee ${ }^{2}$ \& S. N. Amirkhanian ${ }^{2}$ \\ ${ }^{I}$ Department of Regional Infrastructure Eng., Kangwon National \\ University, Chun Cheon, Korea \\ ${ }^{2}$ Department of Civil Engineering, Clemson University, Clemson, SC, \\ USA
}

\begin{abstract}
The asphalt binder is modified using the crumb rubber from scrap tires to improve its performance in the pavement on street and highways in an urban area setting. In this study, the rutting resistance index $\left(\mathrm{G}^{*} / \sin \delta\right)$ and chemical composition of rubber-modified binders (RMB) were evaluated using a dynamic shear rheometer and a gel-permeation chromatography system respectively. A source of PG 64-22 asphalt was used for preparing a total of 12 RMB binders. Routine Superpave binder testing was carried out; RMB as the original binder and then RTFO-aged binder as RTFO in DSR test at high temperatures. From chromatogram data, the correlation of large molecular size (LMS) with $\mathrm{G}^{*} / \sin \delta$ was evaluated by service temperatures, 70 and $76^{\circ} \mathrm{C}$. A significant correlation was found between LMS and $\mathrm{G}^{*} / \sin \delta$. The size and type of CRM were significant factors affecting the rheology of the binders. The values of $\mathrm{G}^{*} / \sin \delta$ could be estimated using LMS and CRM size by temperature with $\mathrm{R}^{2}$ of over 0.92 by the developed prediction model.
\end{abstract}

Keywords: asphalt, pavement, chromatogram, scrap tire, rheology, rutting.

\section{Introduction}

Rutting or permanent deformation is a serious distress mechanism in the street pavements in urban areas around the world. The premature distress, compared with rural areas, in various forms occurring in urban pavements due to heavy volume of traffic and congestion requires more and costly maintenance work. The premature distress, sometimes, creates congestion of traffic due to the 
maintenance operation. The best way of solving this problem is to prevent the premature damage and extend service life of urban area pavements by improving quality of materials to be used.

Various polymeric materials are added into the asphalt binder for improving the asphalt binder properties. The rubber from scrap tires or crumb rubber modifier (CRM) is one of the methods used for modifying the binder. The most convincing result of the modification is to improve high-temperature performance grade (PG) of the binder, although the type, content and particle size of rubber are factors affecting the level of the improvement. Stiffness increase is the major reason why the rubber-modified binder (RMB) has improved the performance (resistance against rutting) at high service temperatures of the flexible pavement.

The asphalt binder with large quantities of high-molecular weight molecules tends to exhibit poor low-temperature behavior (or cracking), but a relatively good high-temperature behavior [1]. Increased high-molecular weight molecule or large molecular size (LMS) results in an increase in viscosity and stiffness of a binder. However, too much increase of the LMS due to severe oxidation results in the material to be susceptible to cracking (i.e., brittle). The gel-permeation chromatograph (GPC) test could measure the molecular size distribution, a chemical property, of a binder. It is a relatively easy process for characterizing asphalt binder chemically by detecting change of the molecular size distribution of the binder. Binder viscosity change due to aging is well reported to be predictable by GPC data [2-6]. Recent technology development makes the GPC equipment and software affordable for many laboratories.

The rheology change, caused by addition of the rubber, is evaluated by many researchers based on binder stiffness, $G^{*} / \sin \delta$, using the dynamic shear rheometer (DSR). The results indicated that the $\mathrm{G}^{*} / \mathrm{sin} \delta$ value increased by adding CRM in various contents with various reaction times; therefore, increasing the PG grade. However, there has not much research done to determine the effects, if any changes, of various contents, size, and type of CRM on $\mathrm{G}^{*} / \sin \delta$, the stiffness of the binder. If the change can be predicted, it will be useful for determining the quantity, size and type of CRM to be added to a specific binder beforehand. It is hypnotized that it is possible to predict the stiffness based on data of molecular size distribution or chromatogram of the binder.

Therefore, the objective of this study is to evaluate the stiffness of RMB and their correlation with GPC data, and to find possibility of predicting rutting resistance of the binder based on factors affecting the PG grade of a binder. In this study, various RMBs were prepared, in the laboratory, using three different sizes of CRM obtained by two different processing methods for achieving these objectives.

\section{Materials and methods}

One source of an asphalt binder, PG 64-22 was used in this study. Two different types of crumb rubber production method (ambient: AMB and cryogenic: CRY) 
were prepared in three different sizes (-14 mesh, -30 mesh and -40 mesh) for this study. The rubber-modified binder (RMB) was made, in the laboratory, by adding a specified amount of rubber slowly into the binder at $180^{\circ} \mathrm{C}$ for the specified reaction time while mixing with a stirrer at $600 \mathrm{rpm}$. A total of 18 RMB binders were prepared from 2 rubber types (AMB and CR), 3 sizes (passing \#14, \#30 and \#40 sieves), 1 content (10\% rubber by wt of binder) and 3 reaction times $(15,30$ and 45 minutes). Each $\mathrm{RMB}$ was tested as the original binder using the dynamic shear rheometer (DSR). The binder was then aged in a short term using a rolling thin film oven (RTFO) and tested as an RTFO binder in the DSR at the same temperature.

Each RMB was tested as the original binder in DSR at the specified high temperature. The RMB was then RTFO-aged and tested as RTFO in DSR at the same temperature. The values of $\mathrm{G}^{*} / \sin \delta$, which represents a measure of the high temperature stiffness or rutting resistance of the binder [1], were measured for the original and RTFO binders. Superpave high-temperature performance grades of these binders were determined from DSR data.

Chromatograms of these binders were measured using a high-performance gel-permeation chromatography (GPC) system as shown in Figure 1. The GPC system, a Waters Breeze equipment with computerized data acquisition software, consisted of a manual injector, a dual head pump, a refract index meter (RI detector), a series of two columns (HR 3 and HR 4E) and a column oven was used for this research project.

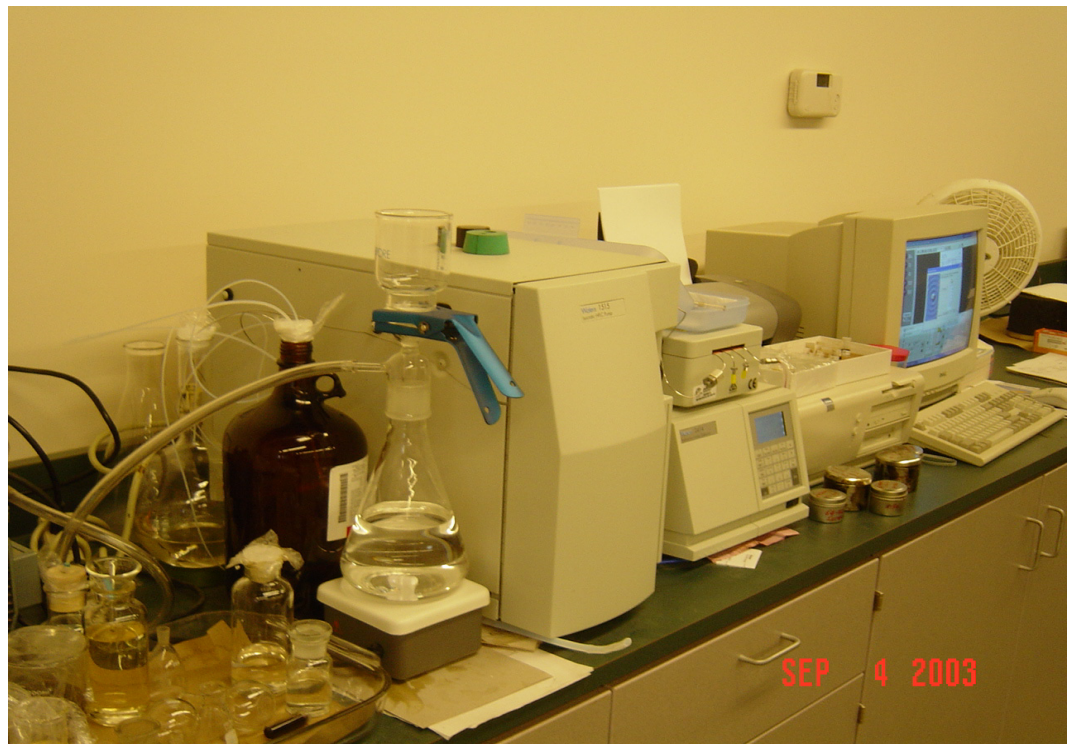

Figure 1: $\quad$ GPC system used in this study.

Tetrahydrofuran (THF) was used as a solvent for dissolving binder and buffer (mobile phase) of the GPC test. A small amount of binder (e.g., 0.05gm) sample 
was dissolved in THF (e.g., 20gm) at the concentration of $0.25 \%(1 / 400)$. The dissolution was filtered by a $0.45 \mu \mathrm{m}$ syringe filter before injection. A $50 \mu \mathrm{l}$ of the filtered sample was injected into the injection module and constituents of the binder were separated by molecular size after the sample passed through the series of columns. The injected sample was transferred by the THF flow into the columns which were kept constantly at $35^{\circ} \mathrm{C}$ in the column oven, in which the flow rate of the mobile phase was $1 \mathrm{ml} / \mathrm{min}$. The asphalt binder molecules were detected by the time they passed the detector and a chromatogram was obtained for each binder sample. Three samples were tested for each binder and aging conditioning and the average value was reported.

Figure 2 shows typical chromatograms of virgin PG64-22 asphalt before and after aging. Some of the rubber particles which were not reacted with asphalt binder were filtered out by the syringe filter. Therefore, the chromatogram of rubberized binder does not show any distinct difference compared with that of virgin PG64-22 in its profile. In this study, a chromatogram profile was partitioned into 13 slices and three parts; large molecular size (LMS; slices 1 to 5), medium molecular size (MMS; 6 to 9) and small molecular size (SMS; 10 to 13), as shown in Figure 2. Defining LMS portion as the front 5 slice was verified in the previous study [7-9]. Among quantitative data of the chromatogram, the LMS value was only used for evaluation in this study. Statistical analyses were performed for evaluating correlation of binder's rheological properties with GPC results.

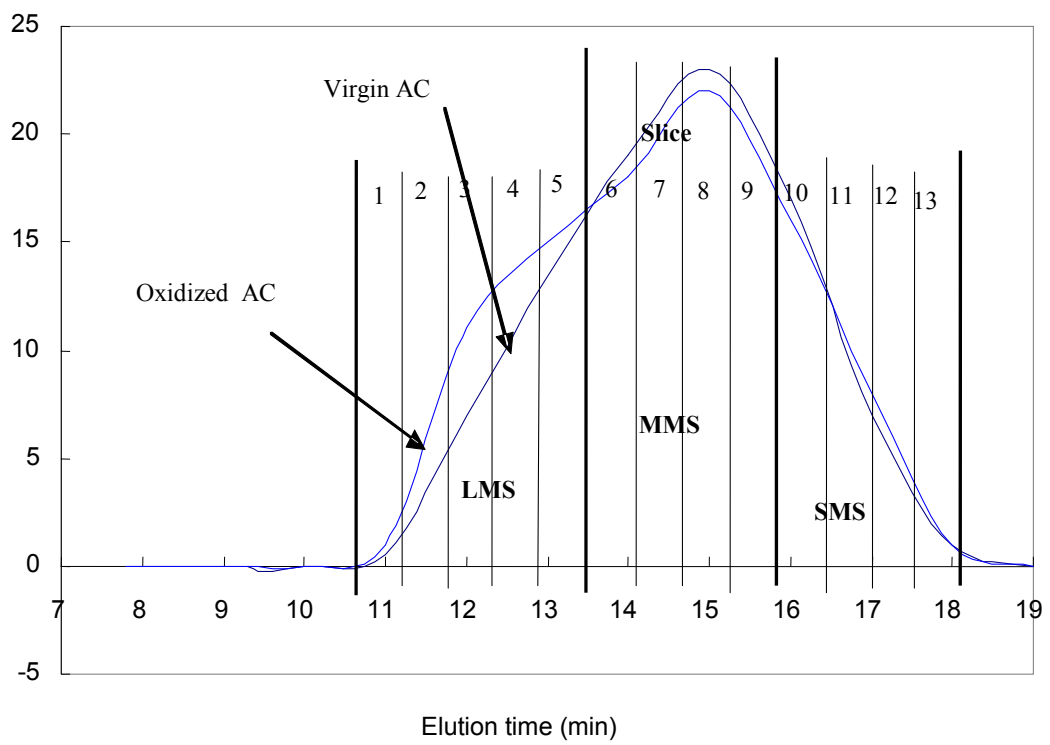

Figure 2: $\quad$ Typical chromatogram of asphalt sample. 


\section{Results and discussion}

GPC and DSR properties of PG 64-22 base binder used in this study are shown in Table 1 as a reference for the analysis of RMB. Table 2 shows statistical analysis results for variables evaluated in this study. Each variable was statistically evaluated to find out if there is a significant difference in $G^{*} / \sin \delta$ values, the high temperature stiffness or rutting resistance [1], within each temperature tested and in LMS values using Duncan's multiple range test at $\alpha=0.05$. Reaction time was the variable which did not show any significance among three reaction times $(15,30$, and 45 minutes). This means that the reaction time does not affect the rutting resistance and the LMS of rubbermodified binder (RMB), and was discarded from test variables. Some variables (e.g., rubber type) indicated significant difference, as shown in Table 3. Since the reaction time was not statistically a significant variable, all binders in three reaction times were considered as one material.

Table 1: LMS and $\mathrm{G}^{*} / \sin \delta$ of PG64-22 binder for virgin and RTFO conditions.

\begin{tabular}{|c|c|c|c|c|c|}
\hline \multirow{2}{*}{ Binder } & \multirow{2}{*}{ Condition } & \multirow{2}{*}{$\begin{array}{c}\text { LMS } \\
\end{array}$} & & \multicolumn{3}{|c|}{$\mathrm{G}^{*} / \sin \delta(\mathrm{kPa})$} \\
\cline { 4 - 6 } & & At $64^{\circ} \mathrm{C}$ & At $70^{\circ} \mathrm{C}$ & At $76^{\circ} \mathrm{C}$ \\
\hline PG64- & Virgin & 12.193 & 1.628 & 0.899 & - \\
\cline { 2 - 6 } 22 & RTFO & 16.04 & - & 2.581 & 1.336 \\
\hline
\end{tabular}

Table 2: $\quad$ Duncan's multiple range test results at $\alpha=0.05$.

\begin{tabular}{|c|c|c|c|}
\hline \multirow{2}{*}{ Variable } & \multicolumn{2}{|c|}{$\mathrm{G}^{*} / \sin \delta$ at } & \multirow{2}{*}{$\begin{array}{c}\text { LMS } \\
(\%)\end{array}$} \\
\cline { 2 - 3 } & $70^{\circ} \mathrm{C}$ & $76^{\circ} \mathrm{C}$ & $\mathrm{S}$ \\
\hline Aging & $\mathrm{S}$ & $\mathrm{S}$ & $\mathrm{NS}$ \\
\hline Particle size & $\mathrm{NS}$ & $\mathrm{S}$ & $\mathrm{NS}$ \\
\hline Reaction time & $\mathrm{NS}$ & $\mathrm{NS}$ & $\mathrm{S}$ \\
\hline Rubber type & $\mathrm{NS}$ & $\mathrm{S}$ & \multicolumn{2}{c}{} \\
\hline
\end{tabular}

Legend: $\mathrm{S}=$ significant, $\mathrm{NS}=$ not significant.

Tables 3 and 4 show measured value of LMS and $G^{*} / \sin \delta$ by particle size and aging level using DSR for determining PG high temperature grade. All of $10 \%$ RMBs were graded as PG 70 in high temperature performance grade, and all of $15 \%$ RMBs were graded as PG76. None of RMBs confirmed to PG 82 specification in this study. The rubber content does have a significant effect on improving performance of the binder. In $10 \% \mathrm{RMB}$ case, a couple of RTFO binders passed Superpave specification limit $(2.2 \mathrm{kPa})$, but the original binder did not meet the limit $(1.0 \mathrm{kPa})$. None of $10 \%$ RMBs were graded as a PG 76 grade.

LMS values show that there was a significant increase by the aging level. LMS values between CRM contents and type were also found to be statistically significant (Table 2). With an increase in LMS, rutting parameter $\left(\mathrm{G}^{*} / \sin \delta\right)$ was observed to increase significantly. It is well known that there is a significant 
correlation between LMS values and binder's physical properties, and rubberized binders seem to produce similar correlations.

Table 5 shows the high temperature performance grade of each binder by CRM type, content and particle size determined from high-temperature DSR test. Figures 3 and 4 show relationships of $\mathrm{G}^{*} / \sin \delta$ value versus LMS value with the coefficient of determination $\left(\mathrm{R}^{2}\right)$ for $10 \%$ and $15 \% \mathrm{RMBs}$, respectively.

Table 3: LMS and $\mathrm{G}^{*} / \sin \delta$ values for each binder combination (CRM 10\%).

\begin{tabular}{|c|c|c|c|c|c|c|}
\hline \multirow{2}{*}{$\begin{array}{l}\text { CMR } \\
\text { Type }\end{array}$} & \multirow{2}{*}{$\begin{array}{c}\text { Content } \\
(\%)\end{array}$} & \multirow{2}{*}{$\begin{array}{c}\text { Size } \\
(\mathrm{mesh})\end{array}$} & \multirow{2}{*}{ Aging } & \multirow{2}{*}{$\begin{array}{c}\text { LMS } \\
(\%)\end{array}$} & \multicolumn{2}{|c|}{$\mathrm{G}^{*} / \sin \delta(\mathrm{kPa})$} \\
\hline & & & & & at $70^{\circ} \mathrm{C}$ & at $76^{\circ} \mathrm{C}$ \\
\hline \multirow{6}{*}{$\mathrm{AMB}$} & \multirow{6}{*}{10} & \multirow{2}{*}{-14} & Original & 14.27 & $1.667 *$ & 0.968 \\
\hline & & & RTFO & 17.88 & $4.434^{*}$ & $2.399 *$ \\
\hline & & \multirow{2}{*}{-30} & Original & 14.24 & $1.681^{*}$ & 0.911 \\
\hline & & & RTFO & 17.59 & $3.800 *$ & 2.161 \\
\hline & & \multirow{2}{*}{-40} & Original & 13.95 & $1.745 *$ & 0.984 \\
\hline & & & RTFO & 16.51 & $3.065^{*}$ & 1.700 \\
\hline \multirow{6}{*}{ CRY } & \multirow{6}{*}{10} & \multirow{2}{*}{-14} & Original & 13.57 & $1.427 *$ & 0.759 \\
\hline & & & RTFO & 16.94 & $3.863^{*}$ & 2.154 \\
\hline & & \multirow{2}{*}{-30} & Original & 14.60 & $1.544^{*}$ & 0.821 \\
\hline & & & RTFO & 18.82 & $4.159 *$ & $2.278^{*}$ \\
\hline & & \multirow{2}{*}{-40} & Original & 13.47 & $1.408^{*}$ & 0.747 \\
\hline & & & RTFO & 16.54 & $3.194 *$ & 1.687 \\
\hline
\end{tabular}

Legend: $\mathrm{AMB}=$ ambient, $\mathrm{CRY}=$ cryogenic, $\mathrm{RTFO}=$ rolling thin film oven, $\mathrm{PAV}=$ pressure aging vessel, * passing Superpave specification.

Table 4: LMS and $\mathrm{G}^{*} / \sin \delta$ values for each binder combination (CRM 15\%).

\begin{tabular}{|c|c|c|c|c|c|c|}
\hline \multirow{2}{*}{$\begin{array}{c}\text { CRM } \\
\text { type }\end{array}$} & \multirow{2}{*}{$\begin{array}{c}\text { Content } \\
(\%)\end{array}$} & \multirow{2}{*}{$\begin{array}{c}\text { Size } \\
(\mathrm{mesh})\end{array}$} & \multirow{2}{*}{ Aging } & \multirow{2}{*}{$\begin{array}{c}\text { LMS } \\
(\%)\end{array}$} & \multicolumn{2}{|c|}{$\mathrm{G}^{*} / \sin \delta(\mathrm{kPa})$} \\
\hline & & & & & at $76^{\circ} \mathrm{C}$ & at $82^{\circ} \mathrm{C}$ \\
\hline \multirow{6}{*}{ AMB } & \multirow{6}{*}{15} & \multirow{2}{*}{-14} & Original & 14.28 & $1.665^{*}$ & 0.982 \\
\hline & & & RTFO & 18.80 & $3.327 *$ & 1.980 \\
\hline & & \multirow{2}{*}{-30} & Original & 14.30 & $1.655^{*}$ & 0.945 \\
\hline & & & RTFO & 19.07 & $4.209 *$ & $2.354^{*}$ \\
\hline & & \multirow{2}{*}{-40} & Original & 13.88 & $2.027 *$ & $1.168^{*}$ \\
\hline & & & RTFO & 16.18 & $3.095 *$ & 1.807 \\
\hline \multirow{6}{*}{ CRY } & \multirow{6}{*}{15} & \multirow{2}{*}{-14} & Original & 13.03 & $1.199 *$ & 0.677 \\
\hline & & & RTFO & 17.88 & $3.343 *$ & 1.865 \\
\hline & & \multirow{2}{*}{-30} & Original & 14.59 & $1.372 *$ & 0.740 \\
\hline & & & RTFO & 24.00 & $3.499 *$ & 1.965 \\
\hline & & \multirow{2}{*}{-40} & Original & 13.76 & $1.391 *$ & 0.782 \\
\hline & & & RTFO & 18.47 & $2.635^{*}$ & 1.518 \\
\hline
\end{tabular}

Legend: $\mathrm{AMB}=$ ambient, $\mathrm{CRY}=$ cryogenic, $\mathrm{RTFO}=$ rolling thin film oven, $\mathrm{PAV}=$ pressure aging vessel, * pass Superpave specification. 
Table 5: $\quad$ Performance grade of each binder.

\begin{tabular}{|c|c|c|c|c|c|c|}
\hline CRM & \multicolumn{3}{|c|}{ Ambient } & \multicolumn{3}{c|}{ Cryogenic } \\
\hline Size (mesh) & -14 & -30 & -40 & -14 & -30 & -40 \\
\hline $\begin{array}{c}\text { RMB10\% High temp. PG } \\
\left({ }^{\circ} \mathrm{C}\right)\end{array}$ & 70 & 70 & 70 & 70 & 70 & 70 \\
\hline $\begin{array}{c}\text { RMB15\% High temp. PG } \\
\left({ }^{\circ} \mathrm{C}\right)\end{array}$ & 82 & 82 & 82 & 76 & 82 & 82 \\
\hline
\end{tabular}

In general, the results indicated that rutting resistance property measured at two service temperatures $\left(70\right.$ and $\left.76^{\circ} \mathrm{C}\right)$ has a very good linear correlation $\left(\mathrm{R}^{2}=\right.$ 0.86 ) with LMS quantity (Figure 3 ). The rutting resistance property measured at two service temperatures $\left(76\right.$ and $\left.82^{\circ} \mathrm{C}\right)$ has also a good, but somewhat lower linear correlation $\left(\mathrm{R}^{2}=0.78\right)$ with LMS quantity (Figure 4). Increasing LMS results in increased rut resistance within each service temperature.

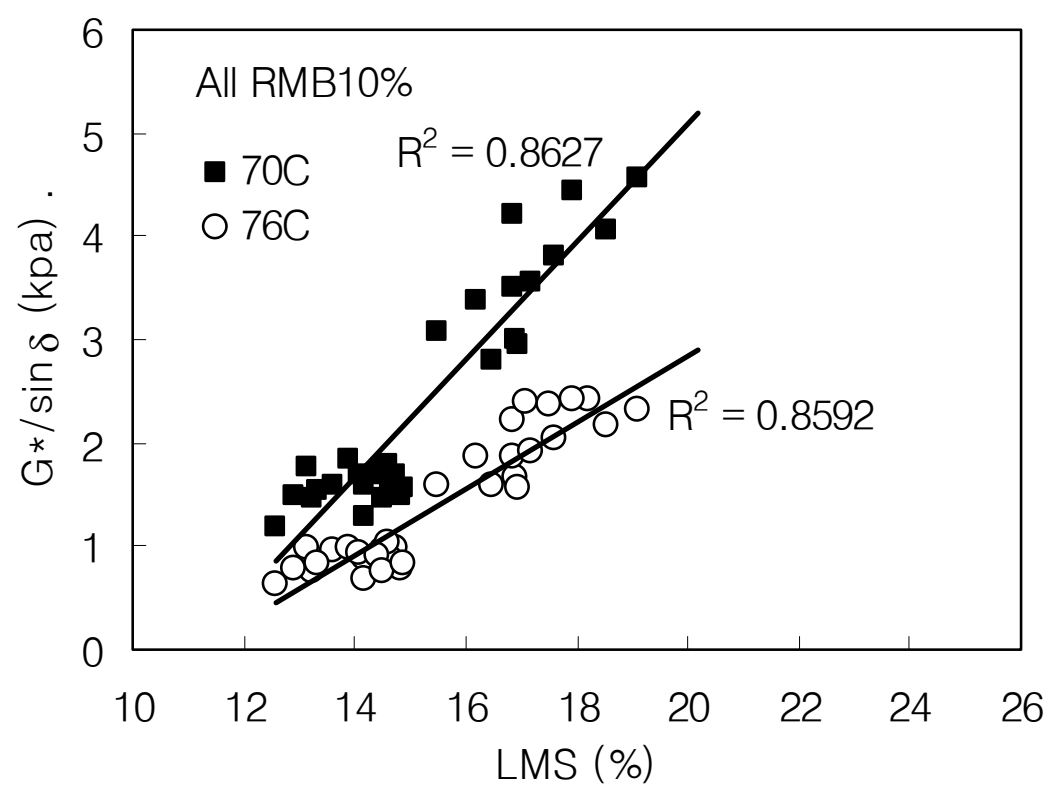

Figure 3: Relationship of $\mathrm{G}^{*} / \sin \delta$ with LMS for CRM (total) modified binder (content: $10 \%$ by wt. of binder).

However, the results indicated that the rutting resistance property of the binder modified with other materials has little correlation with LMS quantity. Increasing LMS does not result in increased rut resistance of binders. For comparison, Table 6 is introduced in this paper to show the correlation of other PMA binders made of polyethylene materials. These binders conformed to PG 88 , but the increase in stiffness did not show a high correlation with an increase 
in LMS values (Figure 5). The reason for this is that the rubber material is reacted well with asphalt oil materials, but PE material is dispersed in asphalt binder without reaction.

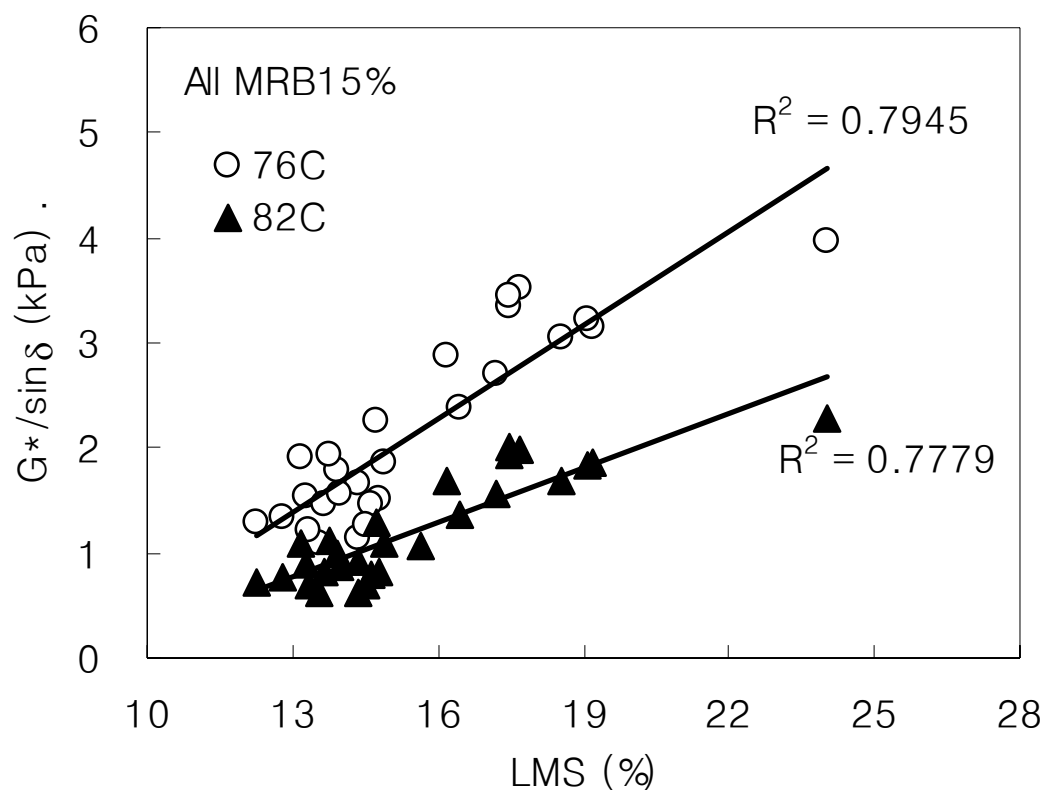

Figure 4: Relationship of $\mathrm{G}^{*} / \sin \delta$ with LMS for CRM (total) modified binder (content: $15 \%$ by wt of binder).

Table 6: $\quad$ LMS and $G^{*} / \sin \delta$ values for each binder combination.

\begin{tabular}{|c|c|c|c|c|c|}
\hline \multicolumn{3}{|c|}{ Materials (\%) } & \multirow{2}{*}{ Aging } & \multirow{2}{*}{$\begin{array}{c}\text { LMS } \\
(\%)\end{array}$} & \multirow{2}{*}{$\begin{array}{c}\mathrm{G}^{*} / \sin \delta \\
(\mathrm{kPa}) \\
\text { at } 88^{\circ} \mathrm{C}\end{array}$} \\
\hline RHDPE & RLDPE & CRM & & & \\
\hline \multirow{2}{*}{4} & \multirow{2}{*}{2} & \multirow{2}{*}{5} & Original & 18.59 & $2.660^{*}$ \\
\hline & & & RTFO & 18.82 & $3.369 *$ \\
\hline \multirow{2}{*}{4} & \multirow{2}{*}{3} & \multirow{2}{*}{5} & Original & 17.30 & $2.507 *$ \\
\hline & & & RTFO & 19.66 & $3.289^{*}$ \\
\hline \multirow{2}{*}{5} & \multirow{2}{*}{3} & \multirow{2}{*}{5} & Original & 13.61 & $1.741^{*}$ \\
\hline & & & RTFO & 23.01 & $2.816^{*}$ \\
\hline \multirow{2}{*}{6} & \multirow{2}{*}{0} & \multirow{2}{*}{5} & Original & 21.67 & $2.233^{*}$ \\
\hline & & & RTFO & 23.23 & $3.263^{*}$ \\
\hline \multirow{2}{*}{7} & \multirow{2}{*}{0} & \multirow{2}{*}{0} & Original & 22.18 & $1.555^{*}$ \\
\hline & & & RTFO & 25.06 & - \\
\hline \multirow{2}{*}{8} & \multirow{2}{*}{0} & \multirow{2}{*}{0} & Original & 16.90 & $2.027 *$ \\
\hline & & & RTFO & 18.09 & - \\
\hline
\end{tabular}

Legend: RHDPE=recycled high-density polyethylene, RLDPE=recycled lowdensity polyethylene, * passing Superpave specification. - no test. 


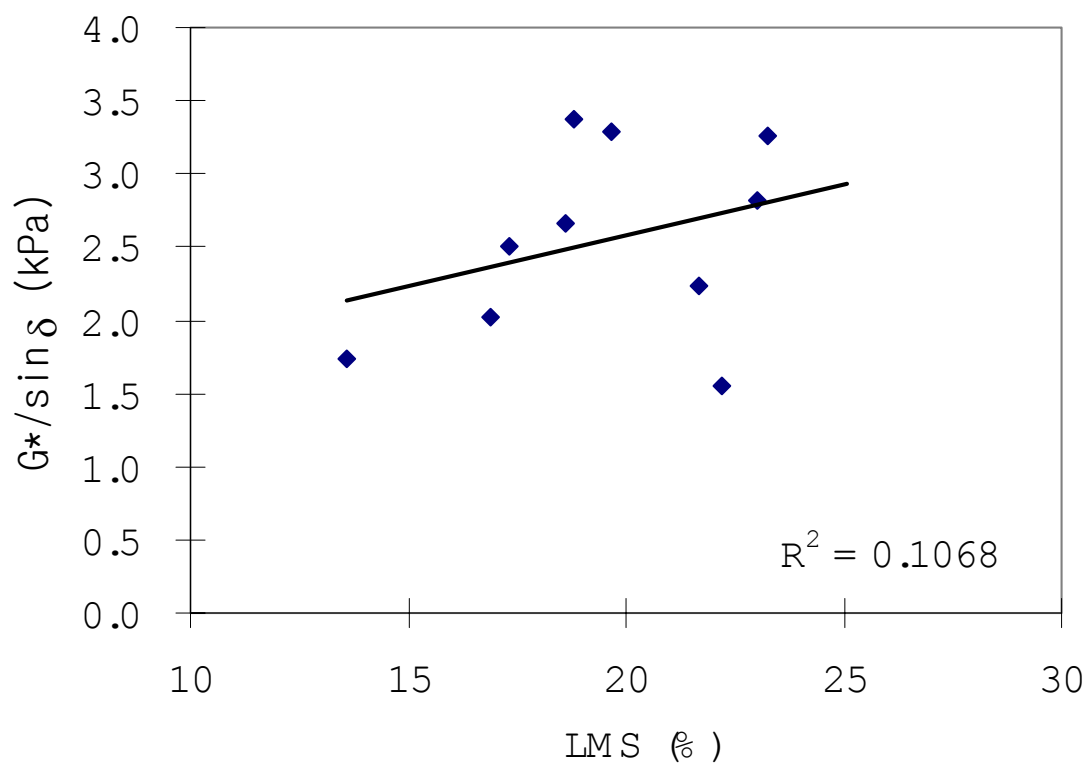

Figure 5: Relationship of $\mathrm{G}^{*} / \sin \delta$ with LMS for recycled PE and CRM modified binder.

Since $\mathrm{G}^{*} / \sin \delta$ had good correlation with LMS and function of CRM content and size, it is possible to estimate this value based on LMS and other variables. Prediction models were developed for $\mathrm{G}^{*} / \mathrm{sin} \delta$ based on regression of these variables by rubber type. The value of $\mathrm{G}^{*} / \sin \delta$ was dependent variable, and LMS, CRM size and content were independent variables. The STEPWISE procedure was performed to select the best model using Statistical Analysis System (SAS). The prediction models for $\mathrm{G}^{*} / \sin \delta$ by CRM type and service temperatures are shown in Table 7.

The average of the above four coefficients of determination $\left(\mathrm{R}^{2}\right)$ for these models is 0.93 and the range is from approximately 0.90 to 0.96 (in Table 7). Between two types of CRM, $\mathrm{R}^{2}$ of the ambient was higher than cryogenic. However, the $\mathrm{R}^{2}$ values are still over 0.9 and, therefore, it is concluded that there is a good possibility of predicting stiffness index if LMS and rubber size values are known.

Figure 6 shows relation of predicted $\mathrm{G}^{*} / \sin \delta$ for ambient (AMB) CRM binder versus cryogenic (CRY) $\mathrm{CRM}$ binder at $70^{\circ} \mathrm{C}$, as an example. These values were produced based on the equations for Ambient $70^{\circ} \mathrm{C}$ and Cryogenic $70^{\circ} \mathrm{C}$ in Table 7 , respectively, using LMS value $\left(\mathrm{X}_{1}\right)$ in the range of $14-18$ and mesh size $\left(\mathrm{X}_{2}\right)$ of 40 . As seen in the figure, data points are very well correlated with a $\mathrm{R}^{2}$ value of 0.98 . Therefore, it is possible to predict the $\mathrm{G}^{*} / \sin \delta$ value of rubber-modified binder based on LMS value and rubber size at the specified temperatures. 
Table 7: $\quad$ Prediction models for $\mathrm{G}^{*} / \sin \delta$ by CRM type and test temperatures.

\begin{tabular}{|c|c|l|c|}
\hline CRM & Temp & \multicolumn{1}{|c|}{ Model } & $\mathrm{R}^{2}$ \\
\hline \multirow{2}{*}{ AMB } & $70^{\circ} \mathrm{C}$ & $\begin{array}{l}\mathrm{Y}=142.02 \mathrm{X}_{1}^{2}+0.7387 \mathrm{X}_{2}^{2}-3844.2 \mathrm{X}_{1}- \\
34.625 \mathrm{X}_{2}+27951\end{array}$ & 0.9422 \\
\cline { 2 - 4 } & $76^{\circ} \mathrm{C}$ & $\begin{array}{l}\mathrm{Y}=-21.57 \mathrm{X}_{1}^{3}+1072 \mathrm{X}_{1}^{2}+0.509 \mathrm{X}_{2}^{2}-17290 \mathrm{X}_{1} \\
-29.6 \mathrm{X}_{2}+92459\end{array}$ & 0.9612 \\
\hline \multirow{2}{*}{$\mathrm{CRY}$} & $70^{\circ} \mathrm{C}$ & $\begin{array}{l}\mathrm{Y}=40.58 \mathrm{X}_{1}^{2}+3.32 \mathrm{X}_{2}^{2}-671.6 \mathrm{X}_{1}-186.4 \mathrm{X}_{2} \\
+5252\end{array}$ & 0.9105 \\
\cline { 2 - 4 } & $76^{\circ} \mathrm{C}$ & $\begin{array}{l}\mathrm{Y}=-17.33 \mathrm{X}_{1}^{2}+2.05 \mathrm{X}_{2}^{2}-215.8 \mathrm{X}_{1}-116.9 \mathrm{X}_{2} \\
+1900\end{array}$ & 0.8995 \\
\hline \multirow{2}{*}{ Total } & $70^{\circ} \mathrm{C}$ & $\begin{array}{l}\mathrm{Y}=-25.9 \mathrm{X}_{1}^{3}+1272 \mathrm{X}_{1}^{2}+1.025 \mathrm{X}_{2}^{2}-20038 \mathrm{X}_{1} \\
-60.76 \mathrm{X}_{2}+104669\end{array}$ & 0.9134 \\
\cline { 2 - 5 } & $76^{\circ} \mathrm{C}$ & $\begin{array}{l}\mathrm{Y}=-18.13 \mathrm{X}_{1}^{3}+876.2 \mathrm{X}_{1}{ }^{2}+0.6658 \mathrm{X}_{2}{ }^{2}- \\
13685 \mathrm{X}_{1}-29.6 \mathrm{X}_{2}-70976\end{array}$ & 0.9230 \\
\hline
\end{tabular}

Legend: $\mathrm{Y}=$ predicted $\mathrm{G}^{*} / \sin \delta(\mathrm{kPa}), \mathrm{X}_{1}=\mathrm{LMS}(\%), \mathrm{X}_{2}=\mathrm{CRM}$ size given by mesh, $\mathrm{X}_{3}=\mathrm{CRM}$ content $(\%$.).

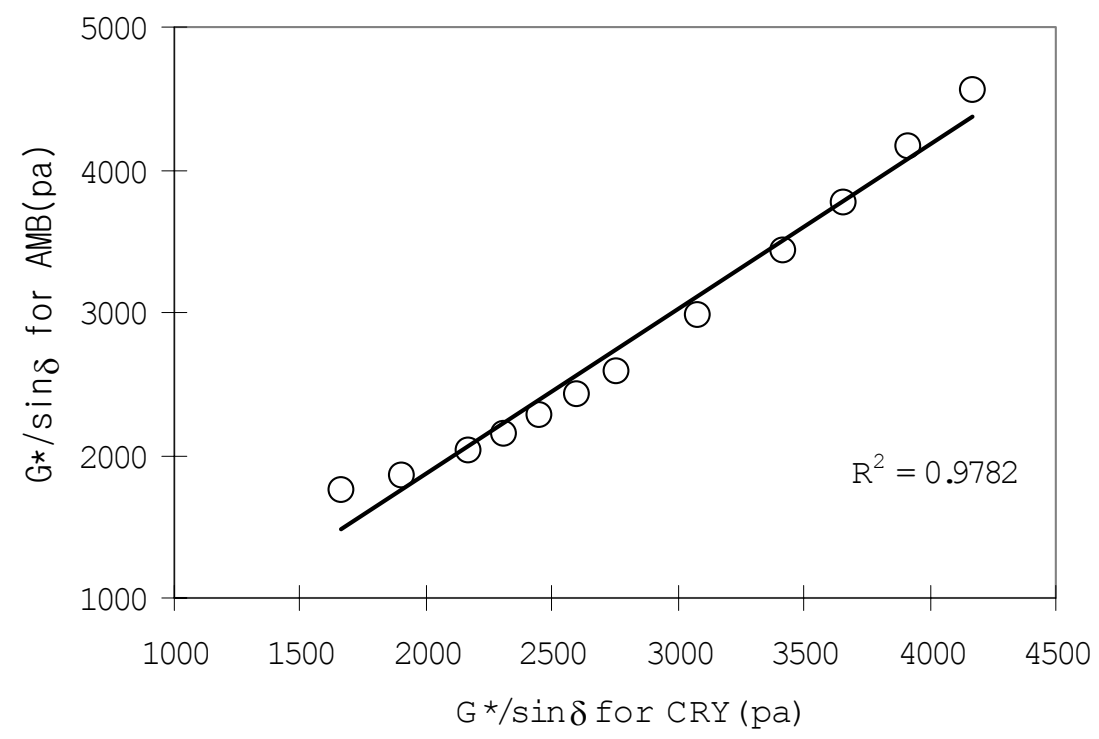

Figure 6: Relation of rutting parameter at $70^{\circ} \mathrm{C}$ for -40 mesh AMB rubber vs. CRY rubber in the range of LMS $14-18 \%$.

\section{Conclusions}

This limited study investigated laboratory evaluation of rubber-modified binder using DSR and GPC. While improving high-temperature grade of binders by increasing stiffness using rubber is not a new idea, however, it is not well known 
whether or not this rheology change is reflected in molecular size distribution or chromatogram of the binder. The results in this study indicated that there is a significant correlation between molecular size distribution (i.e., LMS) and the rutting resistance property (i.e., $\mathrm{G}^{*} / \sin \delta$ ) of binder.

The size and type of CRM were significant factors affecting the rheology of the binders. The value of $\mathrm{G}^{*} / \mathrm{sin} \delta$ could be estimated using LMS and CRM size by the developed prediction model for the binders used in this research. The coefficient of determination, $\mathrm{R}^{2}$, was over 0.92 on the average with maximum of 0.96 for the prediction models. However, the rutting property of the PMA using other materials such as PE cannot be predicted as well. Therefore, the rutting property of rubber-modified binder (RMB) can be well predicted if the LMS of the binder and the size of CRM are known. This is a good advantage to have in the field because the size and content of CRM could be controlled through the production and even tested beforehand; therefore, leading in producing binders for longer service life for urban area pavements.

\section{Acknowledgements}

This study was supported by the Asphalt Rubber Technology Service (ARTS), Civil Engineering Department, Clemson University, Clemson, SC, USA, and by the Kangwon National University, Chun Cheon, Korea.

\section{References}

[1] Yapp, M., Durrani, A. Z. \& Finn, F. N., "HP-GPC and asphalt characterization literature review," SHRP-A/ULR-91-503, SHRP, NRC, Washington, D. C. 1991.

[2] Kim, K. W. and Burati, J. L. (1993). "Use of GPC chromatogram to characterize aged asphalt cements." Journal of Materials in Civil Engineering, ASCE, Vol. 5 (1), 41-52.

[3] Kim, K. W., Doh, Y. S. and Amirkhanian, S. N. (2004). "Effect of polymers on aging of asphalt binder." Journal of Korean Society of Pavement Engineers, Vol. 6 (2).

[4] Asi. I. M., Wahhab, H. I. A. A. Dubabi, I. A. and Ali, M. F. (1997). "Performance modeling of Arabian asphalt using HP-GPC." Journal of Materials Engineering and Performance, Vol. 6 (4).

[5] Kim, K. W., Burati, J. L. and J. S. Park. (1995). "Methodology for defining LMS portion in asphalt chromatogram." Journal of Materials in Civil Engineering, ASCE, Vol. 7 (1), 31-40.

[6] Wahhab. H. I. A. A., Asi, I. M., Ali, F. M. and Dubabi, I. A. A. (1999). "Prediction of asphalt rheological properties using HP-GPC." Journal of Materials in Civil Eng., ASCE, 11(1). 